\title{
Molecular Investigation of Zoonotic Intestinal Protozoa in Pet Dogs and Cats in Yunnan Province, Southwestern China
}

\author{
Yu-Gui Wang ${ }^{1,2,3}$, Yang Zou ${ }^{2, *} \mathbb{D}$, Ze-Zhong Yu ${ }^{4}$, Dan Chen ${ }^{5}$, Bin-Ze Gui ${ }^{3}$, Jian-Fa Yang ${ }^{1}$, Xing-Quan Zhu ${ }^{1,6} \mathbb{D}$, \\ Guo-Hua Liu ${ }^{3}$ and Feng-Cai Zou ${ }^{1, *}$
}

1 Key Laboratory of Veterinary Public Health of Yunnan Province, College of Veterinary Medicine, Yunnan Agricultural University, Kunming 650201, China; wyg18894032073@outlook.com (Y.-G.W.); 2002012@ynau.edu.cn (J.-F.Y.); xingquanzhu1@hotmail.com (X.-Q.Z.)

2 State Key Laboratory of Veterinary Etiological Biology, Key Laboratory of Veterinary Parasitology of Gansu Province, Lanzhou Veterinary Research Institute, Chinese Academy of Agricultural Sciences, Lanzhou 730046, China

3 Hunan Provincial Key Laboratory of Protein Engineering in Animal Vaccines, College of Veterinary Medicine, Hunan Agricultural University, Changsha 410128, China; GBZ296936@163.com (B.-Z.G.); liuguohua@hunau.edu.cn (G.-H.L.)

4 Department of Animal Science, Yuxi Agricultural Vocation Technical College, Yuxi 653106, China; yzznzy2021@163.com

5 School of Life Science, Fudan University, Shanghai 200438, China; 20110700150@fudan.edu.cn

6 College of Veterinary Medicine, Shanxi Agricultural University, Taigu 030801, China

Citation: Wang, Y.-G.; Zou, Y.; Yu, Z.-Z.; Chen, D.; Gui, B.-Z.; Yang, J.-F.; Zhu, X.-Q.; Liu, G.-H.; Zou, F.-C. Molecular Investigation of Zoonotic Intestinal Protozoa in Pet Dogs and Cats in Yunnan Province,

Southwestern China. Pathogens 2021, 10, 1107. https://doi.org/10.3390/ pathogens 10091107

Academic Editors: David Carmena, David González-Barrio and Pamela Carolina Köster

Received: 4 August 2021

Accepted: 23 August 2021

Published: 30 August 2021

Publisher's Note: MDPI stays neutral with regard to jurisdictional claims in published maps and institutional affiliations.

Copyright: (c) 2021 by the authors. Licensee MDPI, Basel, Switzerland. This article is an open access article distributed under the terms and conditions of the Creative Commons Attribution (CC BY) license (https:/ / creativecommons.org/licenses/by/ $4.0 /)$.

\begin{abstract}
Giardia duodenalis, Enterocytozoon bieneusi and Cryptosporidium spp. are common enteric pathogens that reside in the intestines of humans and animals. These pathogens have a broad host range and worldwide distribution, but are mostly known for their ability to cause diarrhea. However, very limited information on prevalence and genotypes of G. duodenalis, E. bieneusi and Cryptosporidium spp. in pet dogs and cats are available in China. In the present study, a total of 433 fecal samples were collected from 262 pet dogs and 171 pet cats in Yunnan province, southwestern China, and the prevalence and the genotypes of G. duodenalis, E. bieneusi and Cryptosporidium spp. were investigated by nested PCR amplification and DNA sequencing. The prevalence of G. duodenalis, E. bieneusi and Cryptosporidium spp. was $13.7 \%(36 / 262), 8.0 \%(21 / 262)$, and $4.6 \%(12 / 262)$ in dogs, and $1.2 \%(2 / 171), 2.3 \%(4 / 171)$ and $0.6 \%(1 / 171)$ in cats, respectively. The different living conditions of dogs is a risk factor that is related with the prevalence of G. duodenalis and E. bieneusi $(p<0.05)$. However, there were no statistically significant difference in prevalence of three pathogens in cats. DNA sequencing and analyses showed that four E. bieneusi genotypes (PtEb IX, CD9, DgEb I and DgEb II), one Cryptosporidium spp. (C. canis) and two G. duodenalis assemblages (C and D) were identified in dogs; two E. bieneusi genotypes (Type IV and CtEb I), one Cryptosporidium spp. (C. felis) and one G. duodenalis assemblage (F) were identified in cats. Three novel E. bieneusi genotypes (DgEb I, DgEb II and CtEb I) were identified, and the human-pathogenic genotypes/species Type IV C. canis and C. felis were also observed in this study, indicating a potential zoonotic threat of pet dogs and cats. Our results revealed the prevalence and genetic diversity of G. duodenalis, E. bieneusi and Cryptosporidium spp. infection in pet dogs and cats in Yunnan province, southwestern China, and suggested the potential threat of pet dogs and cats to public health.
\end{abstract}

Keywords: Giardia duodenalis; Enterocytozoon bieneusi; Cryptosporidium spp.; zoonotic genotypes; pet dogs and cats; Yunnan province; China

\section{Introduction}

Giardia duodenalis, Cryptosporidium spp. and Enterocytozoon bieneusi are three eukaryotic unicellular protozoans, which are the causative pathogens of giardiasis, cryptosporidiosis, and microsporidiosis, respectively [1-4]. These pathogens can cause many gastrointestinal 
symptoms such as abdominal pain, nausea, vomiting, anorexia and weight loss especially acute and chronic diarrhea [5-10]. Humans and various animals can be infected by G. duodenalis, Cryptosporidium spp. and E. bieneusi through fecal-oral transmission of their cysts or spores [11,12].

At present, eight $G$. duodenalis assemblages $(\mathrm{A}-\mathrm{H})$ have been identified by the molecular biological detection method [13]. Among these genotypes, assemblages A and B are regarded as zoonotic assemblages which mainly infect humans and other mammals [14]. Other $\mathrm{G}$. duodenalis assemblages $(\mathrm{C}-\mathrm{H})$ are commonly considered as host-specific, while assemblages $\mathrm{C}$ and $\mathrm{D}$ are usually canine-specific assemblages, and assemblage $\mathrm{F}$ is usually a feline-specific assemblage $[15,16]$. However, assemblages $\mathrm{E}$ and $\mathrm{F}$ have also been detected in humans $[17,18]$. In total, over 40 Cryptosporidium species have been reported, and over 21 species have been reported in humans, including C. canis and C. felis, which cause the vast majority of infections in dogs and cats, respectively [12,19]. Moreover, Cryptosporidium muris, Cryptosporidium paroum and Cryptosporidium ubiquitum have also been reported in dogs and cats $[6,7,20-24]$. Enterocytozoon bieneusi is the most common species causing human gut infections among nearly 1500 microsporidian species [23]. At least 500 E. bieneusi genotypes have been defined thus far, which can be divided into several genetically isolated groups, including zoonotic groups (Group 1 and Group 2) and host adapted groups (Groups 3 to 11) [23,24].

Due to the closer relationships between humans with pet dogs and cats, many pathogens can be transmitted to humans through pet dogs and cats, including G. duodenalis, Cryptosporidium spp. and E. bieneusi. Therefore, investigation of the prevalence and genotypes/species of G. duodenalis, Cryptosporidium spp. and E. bieneusi in pet dogs and cats will improve our understanding of the potential threat posed by these pathogens in companion animals in Yunnan province, China.

\section{Results}

2.1. Prevalence of G. duodenalis, E. Bieneusi and Cryptosporidium spp. in Pet Dogs and Cats

The prevalence of G. duodenalis, Cryptosporidium spp. and E. bieneusi was $13.7 \%$ (95\%CI 9.6-17.9), 4.6\% (95\%CI 2.0-7.1), 8.0\% (95\%CI 4.7-11.3) in dogs; and it was 1.2\% (95\%CI $0-2.8), 0.6 \%(95 \% \mathrm{CI} 0-1.7)$ and $2.3 \%(95 \% \mathrm{CI} 0.1-4.6)$ in cats, respectively (Table 1$)$. Among three regions, the prevalence of G. duodenali in dogs in Kunming city was significantly higher than that in Chuxiong city and Lijiang city $(p<0.05)$. Moreover, the prevalence of G. duodenalis in dogs in shelter dogs $(27.8 \%, 20 / 72,95 \%$ CI 17.4-38.1) was higher than that in pet markets $(2.9 \%, 1 / 34,95 \%$ CI $0-8.6)$ and pet hospitals $(9.6 \%, 15 / 156,95 \%$ CI 5.0-14.2), and the difference was statistically significant $(p<0.001)$. However, no statistically significant difference in prevalence of G. duodenalis in pet cats was observed (Table 1).

Among the different living conditions of dogs, the difference in E. bieneusi prevalence was statistically significant $(p<0.001)$. The prevalence of E. bieneusi in dogs aged more than 6 months was $10.3 \%$ (95\%CI 6.0-14.6), which was significantly higher than that in dogs aged less than 6 months $(1.5 \%, 95 \%$ CI 0-4.3) (Table 1). Also, the prevalence of E. bieneusi in female dogs was 10.3\% (95\%CI 5.5-15.1), which was higher than that in male dogs (4.7\%, 95\%CI 0.7-8.7), but the difference in prevalence was not statistically significant $(p=0.098)$. Similarly, the prevalence of E. bieneusi in female cats $(3.3 \%, 95 \%$ CI 0-7.9) was slightly higher than that in male cats $(1.8 \%, 95 \%$ CI $0-4.3)$ (Table 1$)$.

Furthermore, the prevalence of Cryptosporidium spp. in dogs in shelter $(15.3 \%, 95 \% \mathrm{CI}$ 7.0-23.6) was higher than that in pet markets (no detection) and pet hospitals $(0.6 \%, 95 \% \mathrm{CI}$ 0-1.9). Between two gender groups, the prevalence of Cryptosporidium spp. in male and female dogs was not significantly different (Table 1). 
Table 1. Factors associated with Giardia duodenalis, Enterocytozoon bieneusi and Cryptosporidium spp. prevalence in pet dogs and cats in Yunnan province, southwestern China.

\begin{tabular}{|c|c|c|c|c|c|c|c|c|c|c|c|c|}
\hline \multirow{2}{*}{ Animals } & \multirow{2}{*}{ Factors } & \multirow{2}{*}{ Category } & \multirow{2}{*}{$\begin{array}{c}\text { No. } \\
\text { Sample }\end{array}$} & \multicolumn{2}{|c|}{ Giardia duodenalis } & \multirow[b]{2}{*}{$p$-Value } & \multicolumn{2}{|c|}{ Enterocytozoon bieneusi } & \multicolumn{4}{|c|}{ Cryptosporidium spp. } \\
\hline & & & & No. Positive & $\%(95 \% \mathrm{CI})$ & & No. Positive & $\%(95 \% \mathrm{CI})$ & $p$-Value & No. Positive & $\%(95 \% \mathrm{CI})$ & $p$-Value \\
\hline \multirow{5}{*}{ Dogs } & & $<6$ months & 68 & 8 & $11.8(4.1-19.4)$ & \multirow[b]{2}{*}{0.582} & 1 & $1.5(0-4.3)$ & \multirow[b]{2}{*}{0.021} & 1 & $1.5(0-4.3)$ & \multirow[b]{2}{*}{0.154} \\
\hline & Age & $>6$ months & 194 & 28 & $14.4(9.5-19.4)$ & & 20 & $10.3(6.0-14.6)$ & & 11 & $5.7(2.4-8.9)$ & \\
\hline & \multirow{3}{*}{ Region } & Kunming & 134 & 26 & $19.4(12.7-26.1)$ & \multirow{3}{*}{0.013} & 18 & $13.4(7.7-19.2)$ & \multirow[t]{3}{*}{-} & 11 & $8.2(3.6-12.9)$ & \multirow[t]{3}{*}{-} \\
\hline & & Lijiang & 90 & 9 & $10.0(3.8-16.2)$ & & 0 & 0 & & 1 & $1.1(0-3.3)$ & \\
\hline & & Chuxiong & 38 & 1 & $2.6(0-7.7)$ & & 3 & $7.9(0-16.5)$ & & 0 & 0 & \\
\hline & \multirow[b]{2}{*}{ Gender } & Male & 107 & 16 & $15.0(8.2-21.7)$ & \multirow[b]{2}{*}{0.636} & 5 & $4.7(0.7-8.7)$ & \multirow[b]{2}{*}{0.098} & 5 & $4.7(0.7-8.7)$ & \multirow[b]{2}{*}{0.95} \\
\hline & & Female & 155 & 20 & $12.9(7.6-18.2)$ & & 16 & $10.3(5.5-15.1)$ & & 7 & $4.5(1.2-7.8)$ & \\
\hline & \multirow{4}{*}{$\begin{array}{l}\text { Living } \\
\text { condition }\end{array}$} & Pet hospital & 156 & 15 & $9.6(5.0-14.2)$ & \multirow{4}{*}{$<0.001$} & 1 & $0.6(0-1.9)$ & \multirow{4}{*}{$<0.001$} & 1 & $0.6(0-1.9)$ & - \\
\hline & & Pet market & 34 & 1 & $2.9(0-8.6)$ & & 3 & $8.8(0-18.4)$ & & 0 & 0 & \\
\hline & & Shelter & 72 & 20 & $27.8(17.4-38.1)$ & & 17 & $23.6(13.8-33.4)$ & & 11 & $15.3(7.0-23.6)$ & \\
\hline & & Subtotal & 262 & 36 & $13.7(9.6-17.9)$ & & 21 & $8.0(4.7-11.3)$ & & 12 & $4.6(2.0-7.1)$ & \\
\hline \multirow{8}{*}{ Cats } & \multirow{3}{*}{ Age } & $<6$ months & 145 & 2 & $1.4(0-3.3)$ & \multirow{2}{*}{-} & 4 & $2.8(0.1-5.4)$ & \multirow{2}{*}{-} & 1 & $0.7(0-2.0)$ & \multirow[t]{2}{*}{-} \\
\hline & & $>6$ months & 26 & 0 & 0 & & 0 & 0 & & 0 & 0 & \\
\hline & & Kunming & 36 & 1 & $2.8(13.1-42.4)$ & \multirow[t]{3}{*}{-} & 0 & 0 & \multirow[t]{3}{*}{ - } & 0 & 0 & - \\
\hline & \multirow[t]{2}{*}{ Region } & Lijiang & 110 & 0 & 0 & & 0 & 0 & & 1 & $0.9(0-2.7)$ & \\
\hline & & Chuxiong & 25 & 1 & $4.0(0-11.7)$ & & 4 & $16.0(1.6-30.4)$ & & 0 & 0 & \\
\hline & & Male & 111 & 2 & $1.8(0-4.3)$ & - & 2 & $1.8(0-4.3)$ & - & 1 & $0.9(0-2.7)$ & - \\
\hline & condition & Shelter & 17 & 0 & 0 & & 0 & 0 & & 0 & 0 & \\
\hline & & Subtotal & 171 & 2 & $1.2(0-2.8)$ & & 4 & $2.3(0.1-4.6)$ & & 1 & $0.6(0-1.7)$ & \\
\hline Total & & & 433 & 38 & $8.8(6.1-11.4)$ & & 25 & $5.8(3.6-8.0)$ & & 13 & $3.0(1.4-4.6)$ & \\
\hline
\end{tabular}




\subsection{Assemblages and Subtypes of G. duodenalis in Pet Dogs and Cats}

PCR amplification and DNA sequencing showed that 38 positive samples (36 from dogs and 2 from cats) of $G$. duodenalis were detected at bg locus, resulting three assemblages, namely C (4 from dogs), D (32 from dogs) and F (2 from cats). In addition, at the gdh locus, the 19 gdh-positive samples were identified as assemblage C ( 4 from dogs), D (13 from dogs) and F (2 from cats). Only one tpi-positive sample (1 from dogs) was identified as assemblage $\mathrm{C}$.

Sequence alignment analysis revealed some single nucleotide polymorphisms at bgsequences, gdh-sequences and tpi-sequences, respectively. At bg locus, one subtype of assemblage $C, 7$ subtypes of assemblage $D$ and one subtype of assemblage $F$ were identified, including five novel (Da4* $\sim \mathrm{Da} 7^{*}, \mathrm{Fa} 1 *$ ) and four known sub-assemblages (Table 2). Also, at gdh gene locus, three subtypes of assemblage $C$, seven subtypes of assemblage $D$ and one subtype of assemblage F were identified, including four novel $\left(\mathrm{Cb} 3 *\right.$, Db5 $\left.{ }^{*} \sim \mathrm{Db} 7 *\right)$ and six known subtypes (Table 2). Only one novel subtype ( $\mathrm{Cc} 1^{*}$ ) of assemblage $\mathrm{C}$ was found at tpi gene locus (Table 2). Moreover, one sample were successfully amplified and sequenced at three gene loci (bg, gdh and tpi), forming one mixed infection (Table 3).

Table 2. Variations in nucleotide sequences of assemblages of Giardia duodenalis in pet dogs and cats in Yunnan province, southwestern China.

\begin{tabular}{|c|c|c|c|c|c|c|c|c|c|}
\hline \multirow[t]{2}{*}{ Locus } & \multicolumn{2}{|l|}{ Host (Subtypes) } & \multicolumn{4}{|c|}{ Nucleotide at Position } & & \multirow[t]{2}{*}{$\begin{array}{c}\text { No. } \\
\text { Positive }\end{array}$} & \multirow[t]{2}{*}{$\begin{array}{c}\text { Accessior } \\
\text { Number }\end{array}$} \\
\hline & (a) Variations in bg nuclec & es am & issen & D & & & & & \\
\hline \multirow{16}{*}{ bg } & & 31 & 61 & 103 & 109 & 203 & & & \\
\hline & Reference sequences & G & A & G & $\mathrm{C}$ & A & & & MG873354 \\
\hline & $\operatorname{Dog}(\mathrm{Da} 1)$ & & & & & & & 20 & MN734349 \\
\hline & Dog (Da2) & & & A & & & & 5 & MN734350 \\
\hline & Dog (Da3) & & & & $\mathrm{T}$ & & & 3 & MN734353 \\
\hline & $\operatorname{Dog}\left(\mathrm{Da}_{4}^{*}\right)$ & & & A & $\mathrm{T}$ & & & 1 & MN734351 \\
\hline & $\operatorname{Dog}\left(\mathrm{Da}^{*}\right)$ & A & & & A & & & 1 & MN734354 \\
\hline & $\operatorname{Dog}\left(\mathrm{Da}^{*}\right)$ & & $\mathrm{C}$ & A & & & & 1 & MN734352 \\
\hline & $\operatorname{Dog}\left(\mathrm{Da}^{*}\right)$ & A & & & A & G & & 1 & MN734355 \\
\hline & (b) Variations in bg nucled & $\begin{array}{l}\text { es an } \\
55\end{array}$ & assen & & & & & & \\
\hline & Reference sequences & $\mathrm{C}$ & & & & & & & KX960131 \\
\hline & Cat $(\mathrm{Fa} 1 *)$ & $\mathrm{T}$ & & & & & & 2 & MN734356 \\
\hline & (c) Variations in bg nucleo & es am & Issem & & & & & & \\
\hline & Reference sequences & & & & & & & & KY979502 \\
\hline & Dog (Ca1) & & & & & & & 4 & MN734348 \\
\hline & (a) Variations in gdh nucle & $\operatorname{ces} \mathbf{a}$ & asse & ge $C$ & & & & & \\
\hline \multirow{18}{*}{ gdh } & & 340 & 589 & 600 & 603 & 693 & & & \\
\hline & Reference sequences & A & G & $\mathrm{C}$ & A & G & & & MF990016 \\
\hline & $\operatorname{Dog}(\mathrm{Cb} 1)$ & G & A & $\mathrm{T}$ & G & & & 2 & MN734358 \\
\hline & $\operatorname{Dog}(\mathrm{Cb} 2)$ & G & A & $\mathrm{T}$ & G & $\mathrm{T}$ & & 1 & MN734359 \\
\hline & $\operatorname{Dog}(\mathrm{Cb} 3 *)$ & & & & G & & & 1 & MN734357 \\
\hline & (b) Variations in gdh nucl & ices a & asse & ge $D$ & & & & & \\
\hline & & 356 & 368 & 386 & 506 & 509 & 654 & & \\
\hline & Reference sequences & C & A & $\mathrm{T}$ & A & C & A & & MF990017 \\
\hline & $\operatorname{Dog}(\mathrm{Db} 1)$ & & & & & & & 1 & MN734366 \\
\hline & $\operatorname{Dog}(\mathrm{Db} 2)$ & $\mathrm{T}$ & G & & & & & 3 & MN734362 \\
\hline & $\operatorname{Dog}(\mathrm{Db} 3)$ & & & A & & & G & 5 & MN734364 \\
\hline & Dog (Db4) & $\mathrm{T}$ & & & & & & 1 & MN734363 \\
\hline & $\operatorname{Dog}\left(\mathrm{Db}^{*}\right)$ & & G & & & & & 1 & MN734361 \\
\hline & $\operatorname{Dog}\left(\mathrm{Db}^{*}\right)$ & & & A & & & & 1 & MN734360 \\
\hline & $\operatorname{Dog}\left(\mathrm{Db}^{*}\right)$ & $\mathrm{T}$ & G & & $\mathrm{T}$ & $\mathrm{T}$ & & 1 & MN734365 \\
\hline & (c) Variations in gdh nucle & ces a & asse & ge $\mathbf{F}$ & & & & & \\
\hline & Reference sequences & & & & & & & & KM977649 \\
\hline & Cat $(\mathrm{Fb} 1)$ & & & & & & & 2 & MN734367 \\
\hline \multirow{4}{*}{ tpi } & Variations in tpi nucleotid & amon & embl & & & & & & \\
\hline & & 135 & 315 & & & & & & \\
\hline & Reference sequences & G & $\mathrm{T}$ & & & & & & KY979494 \\
\hline & $\operatorname{Dog}\left(\mathrm{Cc}^{*}\right)$ & $\mathrm{T}$ & C & & & & & 1 & MN734368 \\
\hline
\end{tabular}

* means novel subtypes of assemblage. 
Table 3. Multilocus characterization of Giardia duodenalis isolates based on the bg, tpi and gdh genes.

\begin{tabular}{ccccccc}
\hline \multirow{2}{*}{ Isolate } & \multicolumn{3}{c}{ Assemblage } & & No. Sequences & MLG Type \\
\cline { 2 - 4 } & bg & tpi & gdh & & 1 & Mixed \\
\hline XSQG34 & $\mathrm{D}$ & $\mathrm{C}$ & $\mathrm{C}$ & 1 & M \\
\hline
\end{tabular}

\subsection{Genotypes of Enterocytozoon bieneusi and Cryptosporidium spp. in Pet Dogs and Cats}

Based on the ITS sequence, a total of four genotypes, including two known genotypes PtEb IX $(n=18)$, CD9 $(n=1)$ in dogs and two novel genotypes DgEb I $(n=1)$ and DgEb II $(n=1)$ were identified in pet dogs, and one known genotype Type IV $(n=3)$ and one novel genotype CtEb I $(n=1)$ were identified in pet cats (Table 4$)$. The phylogenetic tree showed that genotypes DgEb I, DgEb II, PtEb IX and CD9 all belonged to the dog-specific group. However, genotypes Type IV and CtEb I belonged to the zoonotic Group 1 (Figure 1). Moreover, mixed infections with more than one genotype of E. bieneusi in dogs and cats were not detected.

Two Cryptosporidium species were identified among the 13 Cryptosporidium-positive samples, including 12 samples of $C$. canis in dogs and one sample of $C$. canis in cats (Table 4). Five nucleotide sequences of $C$. canis obtained in this study had $100 \%$ similarity to those deposited sequences in GenBank under accession numbers MN696800. Other sequences of C. canis had $99 \%$ similarity to those deposited sequences in GenBank under accession number KR999984 and KT749818, respectively (Table 4). Moreover, only one C. canis sequence had $97 \%$ similarity to those deposited sequences in GenBank under accession number KM977642 (Table 4).

Table 4. Species or genotypes of Cryptosporidium spp. and Enterocytozoon bieneusi in pet dogs and cats in Yunnan province, southwestern China.

\begin{tabular}{|c|c|c|c|}
\hline Hosts & $\begin{array}{l}\text { Enterocytozoon bieneusi } \\
\text { Genotype (No.) }\end{array}$ & \multicolumn{2}{|c|}{ GenBank Accession Number in This Study } \\
\hline Dog & $\mathrm{DgEb} I *(1)$ & \multicolumn{2}{|c|}{ MZ542370 } \\
\hline Dog & CD9 (1) & \multicolumn{2}{|c|}{ MZ542369 } \\
\hline Dog & $\operatorname{DgEb} \mathrm{II}^{*}(1)$ & \multicolumn{2}{|c|}{ MZ542373 } \\
\hline Dog & PtEb IX (1) & \multicolumn{2}{|c|}{ MZ542371 } \\
\hline Dog & PtEb IX (17) & \multicolumn{2}{|c|}{ MZ542372 } \\
\hline Cat & Type IV (3) & \multicolumn{2}{|c|}{ MZ542374 } \\
\hline Cat & $\mathrm{CtEb} \mathrm{I}^{*}(1)$ & \multicolumn{2}{|c|}{ MZ542375 } \\
\hline Hosts & $\begin{array}{l}\text { Cryptosporidium spp. } \\
\text { Genotype (No.) }\end{array}$ & $\begin{array}{c}\text { Reference Sequences GenBank } \\
\text { Accession Number }\end{array}$ & Similarity \\
\hline Dog & C. canis (5) & MN696800 & $100 \%$ \\
\hline Dog & C. canis (4) & KR999984 & $99 \%$ \\
\hline Dog & C. canis (3) & KT749818 & $99 \%$ \\
\hline Cat & C. felis (1) & KM977642 & $97 \%$ \\
\hline
\end{tabular}




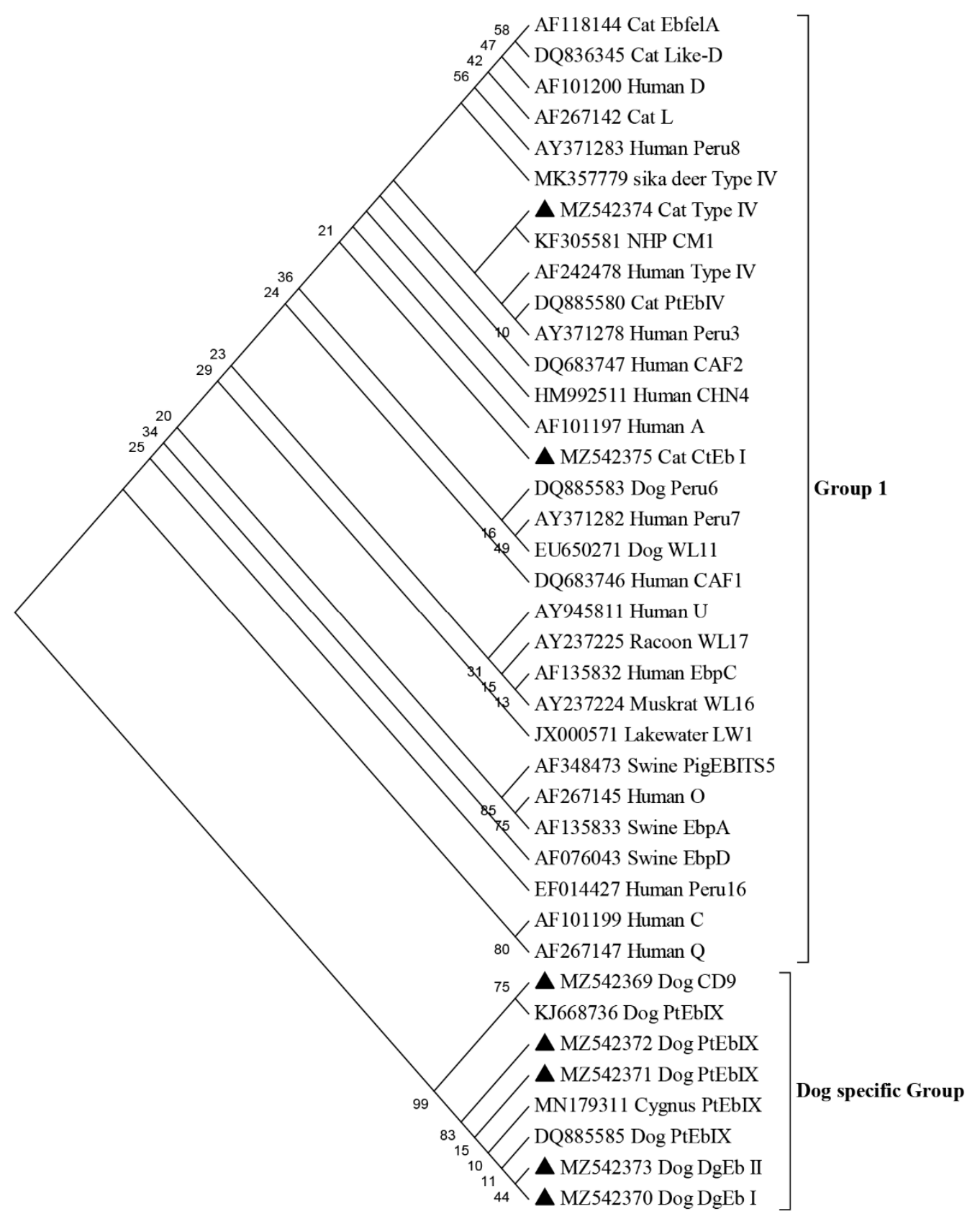

Figure 1. Phylogenetic relationship based on ITS sequences of Enterocytozoon bieneusi in pet dogs and cats in Yunnan province, southwestern China. (Note: The samples in this study are indicated by triangles).

\section{Discussion}

Dogs and cats, as domestic animals, share a common environment with humans and other animals, and can infect them with various unicellular zoonotic pathogens. Thus far, many studies about the infection of G. duodenalis, Cryptosporidium spp. and E. bieneusi in dogs and cats have been recorded worldwide, such as Asia, Europe and Latin America, although only a few have been reported in Africa (Table 5) [6,7,16,20,25-53]. According to the studies in China, the prevalence of $G$. duodenalis ranges from $4.5-26.2 \%$ in dogs and $1.9-13.1 \%$ in cats $[6,7,25,26]$; the prevalence of Cryptosporidium spp. ranges from $3.1-7.5 \%$ in dogs and $5.6-5.8 \%$ in cats $[6,7,46,47]$; and the prevalence of E. bieneusi ranges from $6.0-13.9 \%$ in dogs and $1.4-11.5 \%$ in cats $[6,7,33-35]$, respectively (Table 5). 
Table 5. Prevalence of Giardia duodenalis, Enterocytozoon bieneusi and Cryptosporidium spp. in dogs and cats in different regions of the world.

\begin{tabular}{|c|c|c|c|c|c|}
\hline Regions & Hosts & Prevalence (\%) & Hosts & Prevalence (\%) & Reference \\
\hline \multicolumn{6}{|c|}{ (a) Prevalence of Giardia duodenalis in dogs and cats in different regions of the world. } \\
\hline \multicolumn{6}{|c|}{ China } \\
\hline Shanghai & Dogs & $26.2 \%$ & Cats & $13.1 \%$ & [7] \\
\hline Guangdong & Dogs & $10.8 \%$ & Cats & $5.8 \%$ & [25] \\
\hline Heilongjiang & Dogs & $4.5 \%$ & Cats & $1.9 \%$ & [6] \\
\hline Sichuan & Dogs & $11.3 \%$ & - & - & [26] \\
\hline Henan & Dogs & $14.3 \%$ & - & - & [27] \\
\hline Hangzhou & - & - & Cats & $1.2 \%$ & [28] \\
\hline Yunnan & Dogs & $13.7 \%$ & Cats & $1.2 \%$ & Present study \\
\hline \multicolumn{6}{|l|}{ Other countries } \\
\hline Australia & Dogs & $6.3 \%$ & Cats & $2.0 \%$ & [20] \\
\hline Greece & Dogs & $25.2 \%$ & Cats & $20.5 \%$ & [29] \\
\hline Spain & Dogs & $33 \%$ & Cats & $9.2 \%$ & [30] \\
\hline Ontario & Dogs & $64.0 \%$ & Cats & $87.0 \%$ & [31] \\
\hline Brazil & Dogs & $19.6 \%$ & - & - & {$[32]$} \\
\hline \multicolumn{6}{|c|}{$\begin{array}{l}\text { (b) Prevalence of Enterocytozoon bieneusi in dogs and cats in different regions of the world. } \\
\text { China }\end{array}$} \\
\hline Shanghai & Dogs & $6.0 \%$ & Cats & $5.6 \%$ & [7] \\
\hline Heilongjiang & Dogs & $6.7 \%$ & Cats & $5.8 \%$ & [6] \\
\hline Henan & Dogs & $13.9 \%$ & Cats & $11.5 \%$ & [33] \\
\hline Eastern China & Dogs & $8.6 \%$ & Cats & $1.4 \%$ & [34] \\
\hline Changchun & Dogs & $7.8 \%$ & - & - & [35] \\
\hline Yunnan & Dogs & $8.0 \%$ & Cats & $2.3 \%$ & Present study \\
\hline \multicolumn{6}{|l|}{ Other countries } \\
\hline Colombia & Dogs & $15.0 \%$ & Cats & $17.4 \%$ & {$[36,37]$} \\
\hline Egypt & Dogs & $13.0 \%$ & Cats & $12.5 \%$ & {$[38]$} \\
\hline Germany & Dogs & $0.0 \%$ & Cats & $5.0 \%$ & [39] \\
\hline Spain & Dogs & $0.8 \%$ & Cats & $3.0 \%$ & [40] \\
\hline Japan & Dogs & $2.5 \%$ & Cats & $14.3 \%$ & [41] \\
\hline Poland & Dogs & $4.9 \%$ & Cats & $9.1 \%$ & [42] \\
\hline Thailand & Dogs & $0.0 \%$ & Cats & $31.3 \%$ & [43] \\
\hline Portugal & Dogs & $100.0 \%$ & Cats & $100.0 \%$ & [44] \\
\hline Iran & Dogs & $25.8 \%$ & Cats & $7.5 \%$ & {$[45]$} \\
\hline \multicolumn{6}{|c|}{$\begin{array}{l}\text { (c) Prevalence of Cryptosporidium spp. in dogs and cats in different regions of the world. } \\
\text { China }\end{array}$} \\
\hline Shanghai & Dogs & $6.0 \%$ & Cats & $5.6 \%$ & [7] \\
\hline Heilongjiang & Dogs & $6.7 \%$ & Cats & $5.8 \%$ & [6] \\
\hline Zhengzhou & Dogs & $3.1 \%$ & - & - & [46] \\
\hline Ya'an & Dogs & $7.5 \%$ & - & - & [47] \\
\hline Yunnan & Dogs & $4.6 \%$ & Cats & $0.6 \%$ & Present study \\
\hline \multicolumn{6}{|l|}{ Other countries } \\
\hline Japan & - & - & Cats & $1.4 \%$ & [48] \\
\hline Spain & Dogs & $5.5 \%$ & Cats & $8.8 \%$ & [16] \\
\hline Germany & Dogs & $1.2 \%$ & Cats & $5.3 \%$ & [49] \\
\hline Greece & Dogs & $5.9 \%$ & Cats & $6.8 \%$ & [29] \\
\hline Thailand & Dogs & $2.1 \%$ & Cats & $2.5 \%$ & [50] \\
\hline Brasil & Dogs & $24.5 \%$ & Cats & $11.1 \%$ & [51] \\
\hline Italy & Dogs & $1.7 \%$ & - & - & [52] \\
\hline Netherland & Dogs & $8.7 \%$ & Cats & $4.6 \%$ & [53] \\
\hline
\end{tabular}

In the present study, the prevalence of G. duodenalis in dogs is higher than that in Heilongjiang (4.5\%) [6], Guangdong (10.8\%) [25] and Sichuan (11.3\%) [26] provinces, China, and is also higher than other zoonotic pathogens in dogs, such as $10.3 \%$ for Babesia canis, 9.1\% for Anaplasma spp., 4.5\% for Leishmania infantum, 1.7\% for Borrelia burgdorferi, $0.4 \%$ for Ehrlichia spp. and 1.7\% for Dirofifilaria immitis in Italy [54], but is lower than that in Henan province (14.3\%) [27], Shanghai city (26.2\%) in China [7] and other countries (Table 5). 
Similarly, the G. duodenalis prevalence in pet cats is consistent with that in Hangzhou city $(1.2 \%)$ [28], China; but is lower than that in Heilongjiang (1.9\%) [6] and Guangdong (5.8\%) provinces [25] and Shanghai city (13.1\%) [7] in China and other countries (Table 5), and is also lower than L. infantum (3.0\%) in Greece and Italy; Rickettsia felis (10.8\%), Rickettisa typhi $(4.2 \%)$, Anaplasma phagocytophilum $(2.4 \%)$ and Ehrlichia canis $(2.4 \%)$ in cats in Italy $[55,56]$. The reason is complicated among different studies because many factors could affect the prevalences such as sample sizes, sample sources, environments, animal welfare, hygiene conditions, age and sex of samples, and the sensitivity of tested methods. Moreover, the living condition is a risk factor $(p<0.05)$ that is significantly related to the prevalence of G. duodenalis in pet dogs in this study. We suspect that the poor sanitation of shelters contributes significantly to nosocomial transmission, adding to the prevalence of G. duodenalis in pet dogs. Furthermore, the higher prevalence of G. duodenalis was detected in pet dogs in Kunming city $(p<0.05)$ (Table 1$)$, which suggests that the region is also a risk factor significantly associated with G. duodenalis infection in this study. In addition, the prevalence of $G$. duodenalis in male dogs was higher than that in female dogs in the present study, which is consistent with observations in other previous studies [2,57], although the difference was not statistically significant $(p>0.05)$. Compared with dogs, cats seem to be less susceptible to infection with G. duodenalis (Table 1). This might be explained by the different living habits of these two animals.

Similar to G. duodenalis, the prevalences of E. bieneusi in pet dogs and cats in different regions are different (Table 5). This is probably because the route and source of infection for dogs or cats in each region may be different. In addition, other factors can also affect the prevalence of E. bieneusi in dogs and cats. Furthermore, statistical analysis showed that a significant difference was observed among pet dogs in shelters, pet markets and pet hospitals (Table 1), which indicates that dogs living in shelters are more easily infected with E. bieneusi than those dogs in pet hospitals and markets. The reason may be the poorer hygiene conditions in shelters compared with pet markets and pet hospitals. Pet dogs aged more than 6 mouths seemed to be more susceptible to infection with E. bieneusi $(p<0.05)$ (Table 1), suggesting that further relevant research should pay more attention to the adult dogs. Additionally, only cats in Chuxiong city were found to be infected by E. bieneusi (Table 1); thus, we speculate that the regional factors may have a significant effect on the prevalence of E. bieneusi in cats. But this hypothesis needs to be tested. Additionally, there was no significant difference in the prevalence of Cryptosporidium spp. rate in pet dogs or cats (Table 1).

Up to now, six assemblages (assemblage A, B, C, D, E and F) have been identified in dogs and cats in previous studies [6,7,25-27,31], and canine-specific and feline-specific assemblages $\mathrm{C}, \mathrm{D}$ and $\mathrm{F}$ are also found in other animals [11]. These findings indicate that both dogs and cats are a reservoir of G. duodenalis, which has risk of transmission among different animals. In the present study, only two assemblages (C and D) were identified in pet dogs, which is similar to previous studies [26,27]. Furthermore, a previous work demonstrated that the assemblages $C$ and $D$ are more sensitive than assemblage $A$ in pet dogs [58]. Moreover, we found nine subtypes of assemblage (at bg locus, $n=4$, at gdh locus, $n=4$ and at tpi locus, $n=1$ ) in dogs and one subtype of assemblage (at bg locus, $n=1$ ) in cats (Table 2). The assemblage of $G$. duodenalis in dogs in the current study seems to more likely to mutate, thus further studies need to examine the genetic structure of these subtypes. Also, one mixed genotype of G. duodenalis was found in dogs in this study (Table 3), revealing the diversity of $G$. duodenalis in our investigation area.

Early studies have reported that genotypes of E. bieneusi CD1 to CD8, D, O, PigEBITSS, EbpA, CMl, Peru8 and EbpC are identified in dogs, and genotypes D, BEB6, I, CC1, CC2, CC3, CC4 are identified in cats in other provinces of China $[33,59]$. In the present study, the dominant genotype of E. bieneusi PtEb IX (18/21) is a common dog-specific E. bieneusi genotype identified in dogs (Table 4). Additionally, two novel genotypes (DgEb I and $\mathrm{DgEb}$ II) were also identified in dogs in our study, which enrich the genotype variety of E. bieneusi in dogs. E. bieneusi genotype Type IV and novel genotype CtEb I in pet cats 
belonged to Group 1 of zoonotic potential (Figure 1), which imply that pet cats may be a potential source of human infection with E. bieneusi in Yunnan province, China.

According to previous studies, C. ubiquitum and C. canis are commonly found in dogs, and C. parvum and C. felis are commonly found in cats in Heilongjiang, Shanghai and other cities or provinces of China [6,7]. In the present study, we only identified C. canis and C. felis in pet dogs and cats, respectively (Table 4). By contrast with the current study, the C. parvum and C. muris have been found in dogs or cats in other countries [20-22,36,60]. Despite our results revealing the presence of host-specific Cryptosporidium spp. species (C. canis and C. felis) in pet dogs and cats, these two species have been reported in humans and mainly in developing countries [6]. This finding suggests that people still need to take further precautions when they are in close contact with their pets. In addition, some nucleotide sequences of Cryptosporidium spp. obtained in pet dogs and cats have mutations in this study (Table 4).

\section{Materials and Methods}

\subsection{Study Sites}

The fecal samples of pet dogs and cats were collected in Kunming city, Lijiang city and Chuxiong city in Yunnan province (Location: $21^{\circ} 8^{\prime} \mathrm{N}$ to $29^{\circ} 15^{\prime} \mathrm{N}$ and $97^{\circ} 31^{\prime} \mathrm{E}$ to $106^{\circ} 11^{\prime}$ E), southwestern China, which covers more than 390,000 square kilometers and has a population of approximately 48 million.

\subsection{Sampling}

During August to September 2018, a total of 433 fresh fecal samples were collected from pet dogs and cats in three cities of Yunnan province, including Kunming city (134 dogs and 36 cats), Lijiang city (90 dogs and 110 cats) and Chuxiong city (38 dogs and 25 cats). The Kunming, Lijiang and Chuxiong cities have more numbers of pet dogs and cats than other cities of Yunnan province, and all the samples of the cats and dogs were randomly collected from the biggest pet hospital, pet market and shelter in each city (i.e., Kunming city, Lijiang city and Chuxiong city), respectively. Moreover, the information regarding regions, ages, genders and living conditions were recorded. All the fecal samples were saved into $15 \mathrm{~mL}$ centrifuge tube with $2.5 \%$ potassium dichromate, and then were stored at $4{ }^{\circ} \mathrm{C}$ until for DNA extraction.

\subsection{Genomic DNA Extraction and PCR Amplification}

Each fecal sample was washed three times with distilled water by centrifuging at $13,000 \mathrm{~g}$ for $5 \mathrm{~min}$ to remove potassium dichromate, and $300 \mathrm{mg}$ of the precipitated samples were used for DNA extraction using the E.Z.N.A. Stool DNA kit (OMEGA, Biotek Inc. USA) according to the manufacturer's instructions. The genomic DNA was stored at $-20^{\circ} \mathrm{C}$ before PCR amplification. The G. duodenalis identification was performed by nested PCR amplification of bg, gdh and tpi gene loci according to previous reports [25,61], Cryptosporidium spp. identification was conducted by nested PCR amplification of the 18S ribosomal RNA [62], and E. bieneusi identification was carried out by nested PCR amplification of ITS rDNA sequences as previously described [63]. The positive and negative controls were included in each PCR reaction. All the secondary PCR products were checked by $2 \%(w / v)$ agarose gel electrophoresis after ethidium bromide staining and visualized under UV light.

\subsection{Sequence Analysis}

The PCR-positive products were sent to Tsingke Biological Technology Company (Xi'an, China) for two-directional sequencing. The obtained sequences were spliced together after initial collation with their DNA peak form graph by Chromas v.2.6. The genotypes/species of G. duodenalis, Cryptosporidium spp. and E. bieneusi were identified by aligning the obtained sequences with corresponding sequences in the GenBank database (http://www.ncbi.lm.nih.gov/GenBank/, accessed on 11 July 2021). The phylogenetic 
tree was established by neighbor-joining method (NJ) with Kimura 2-parameter model in MEGA 7.0 (http://www.megasoftware.net/, accessed on 11 July 2021). The novel genotypes of E. bieneusi were decided by the $\sim 243$-bp ITS region $[64,65]$.

\subsection{Statistical Analysis}

Prevalence of G. duodenalis, Cryptosporidium spp. and E. bieneusi in age, regio, gender and living conditions groups were analyzed using Chi-square test in SPSS 24.0 (SPSS Inc., Chicago, IL, USA). The $95 \%$ confidence intervals (CIs) were estimated. The difference was considered statistically significant when $p$-value $<0.05$.

\section{Conclusions}

The present investigation revealed the prevalence and assemblages/genotypes/species of G. duodenalis, E. bieneusi and Cryptosporidium spp. in pet dogs and cats in Yunnan province, China. The infection with G. duodenalis, E. bieneusi and Cryptosporidium spp. in dogs and cats suggests that we should take measures to prevent and control those pathogens from being transmitted to other animals and humans. Our data provided the valuable information for a better understanding of the epidemiology and public health threat of Giardiasis, E. bieneusi and Cryptosporidium spp. in pet dogs and cats in southwestern China.

Author Contributions: F.-C.Z., Y.Z. and X.-Q.Z. conceived and designed the study. Y.-G.W. performed the experiments, analyzed the data and drafted the manuscript. Y.Z., Z.-Z.Y., D.C., B.-Z.G., J.-F.Y. and G.-H.L. participated in the implementation of the study. X.-Q.Z., F.-C.Z., Y.Z. and Y.-G.W. critically revised the manuscript. All authors have read and agreed to the published version of the manuscript.

Funding: This work was supported by the Yunnan Expert Workstation (Grant No. 202005AF150041), the Veterinary Public Health Innovation Team of Yunnan Province (Grant No. 202105AE160014), the Fund for Shanxi "1331 Project" (Grant No. 20211331-13) and the Agricultural Science and Technology Innovation Program (ASTIP) (Grant No. CAAS-ASTIP-2016-LVRI-03). The funders had no role in the design of the study; in the collection, analyses, or interpretation of data; in the writing of the manuscript, or in the decision to publish the results.

Institutional Review Board Statement: The study protocol has been reviewed and approved by the institutional animal ethical committee of Lanzhou Veterinary Research Institute, Chinese Academy of Agricultural Sciences. The approval code: AECLVRI-2018-003.

Informed Consent Statement: Not applicable.

Data Availability Statement: The data that support the figures within this paper and other finding of this study are available from the corresponding authors upon reasonable request. All of the obtained representative G. duodenalis bg, gdh and tpi nucleotide sequences were deposited in GenBank (https:/ / www.ncbi.nlm.nih.gov/ accessed on 26 November 2019) under the accession numbers MN734348- MN734356, MN734357-MN734367 and MN734368, respectively. The nucleotide sequences of Cryptosporidium spp. and E. bieneusi were deposited in GenBank under accession numbers MZ540366-MZ540371 and MZ542369-MZ542375, respectively.

Conflicts of Interest: The authors declare no conflict of interest.

\section{References}

1. Lagunas-Rangel, F.A.; Bermúdez-Cruz, R.M. Epigenetics in the early divergent eukaryotic Giardia duodenalis: An update. Biochimie 2019, 156, 123-128. [CrossRef]

2. Li, J.; Zhang, P.; Wang, P.; Alsarakibi, M.; Zhu, H.; Liu, Y.; Meng, X.; Li, J.; Guo, J.; Li, G. Genotype identification and prevalence of Giardia duodenalis in pet dogs of Guangzhou, Southern China. Vet. Parasitol. 2012, 188, 368-371. [CrossRef]

3. Ortega-Pierres, M.G.; Jex, A.R.; Ansell, B.R.E.; Svärd, S.G. Recent advances in the genomic and molecular biology of Giardia. Acta Trop. 2018, 184, 67-72. [CrossRef]

4. Li, W.; Li, Y.; Song, M.; Lu, Y.; Yang, J.; Tao, W.; Jiang, Y.; Wan, Q.; Zhang, S.; Xiao, L. Prevalence and genetic characteristics of Cryptosporidium, Enterocytozoon bieneusi and Giardia duodenalis in cats and dogs in Heilongjiang province, China. Vet. Parasitol. 2015, 208, 125-134. [CrossRef] 
5. Tungtrongchitr, A.; Sookrung, N.; Indrawattana, N.; Kwangsi, S.; Ongrotchanakun, J.; Chaicumpa, W. Giardia intestinalis in Thailand: Identification of genotypes. J. Health Popul. Nutr. 2010, 28, 42-52. [CrossRef] [PubMed]

6. Vivancos, V.; González-Alvarez, I.; Bermejo, M.; Gonzalez-Alvarez, M. Giardiasis: Characteristics, Pathogenesis and New Insights about Treatment. Curr. Top. Med. Chem. 2018, 18, 1287-1303. [CrossRef] [PubMed]

7. Xu, H.; Jin, Y.; Wu, W.; Li, P.; Wang, L.; Li, N.; Feng, Y.; Xiao, L. Genotypes of Cryptosporidium spp. Enterocytozoon bieneusi and Giardia duodenalis in dogs and cats in Shanghai, China. Parasit. Vectors 2016, 9, 121.

8. Lucio-Forster, A.; Griffiths, J.K.; Cama, V.A.; Xiao, L.; Bowman, D.D. Minimal zoonotic risk of cryptosporidiosis from pet dogs and cats. Trends Parasitol. 2010, 26, 174-179. [CrossRef] [PubMed]

9. Ballweber, L.R.; Xiao, L.; Bowman, D.D.; Kahn, G.; Cama, V.A. Giardiasis in dogs and cats: Update on epidemiology and public health significance. Trends Parasitol. 2010, 26, 180-189. [CrossRef]

10. Rossle, N.F.; Latif, B. Cryptosporidiosis as threatening health problem: A review. Asian Pac. J. Trop. Biomed. 2013, 3, 916-924. [CrossRef]

11. Heyworth, M.F. Giardia duodenalis genetic assemblages and hosts. Parasite 2016, 23, 13. [CrossRef]

12. Ryan, U.; Hijjawi, N.; Xiao, L. Foodborne cryptosporidiosis. Int. J. Parasitol. 2018, 48, 1-12. [CrossRef]

13. Monis, P.T.; Caccio, S.M.; Thompson, R.C. Variation in Giardia: Towards a taxonomic revision of the gene. Trends Parasitol. 2009, 25, 93-100. [CrossRef] [PubMed]

14. Vanni, I.; Cacciò, S.M.; van Lith, L.; Lebbad, M.; Svärd, S.G.; Pozio, E.; Tosini, F. Detection of Giardia duodenalis assemblages A and B in human feces by simple, assemblage-specific PCR assays. PLoS Negl. Trop. Dis. 2012, 6, e1776. [CrossRef] [PubMed]

15. Adell-Aledón, M.; Köster, P.C.; de Lucio, A.; Puente, P.; Hernández-de-Mingo, M.; Sánchez-Thevenet, P.; Dea-Ayuela, M.A.; Carmena, D. Occurrence and molecular epidemiology of Giardia duodenalis infection in dog populations in eastern Spain. BMC Vet. Res. 2018, 14, 26. [CrossRef] [PubMed]

16. de Lucio, A.; Bailo, B.; Aguilera, M.; Cardona, G.A.; Fernández-Crespo, J.C.; Carmena, D. No molecular epidemiological evidence supporting household transmission of zoonotic Giardia duodenalis and Cryptosporidium spp. from pet dogs and cats in the province of Álava, Northern Spain. Acta Trop. 2017, 170, 48-56. [CrossRef]

17. Abdel-Moein, K.A.; Saeed, H. The zoonotic potential of Giardia intestinalis assemblage E in rural settings. Parasitol. Res. 2016, 115, 3197-3202. [CrossRef]

18. Pipiková, J.; Papajová, I.; Majláthová, V.; Šoltys, J.; Bystrianska, J.; Schusterová, I.; Vargová, V. First report on Giardia duodenalis assemblage $\mathrm{F}$ in Slovakian children living in poor environmental conditions. J. Microbiol. Immunol. Infect. 2020, 53, 148-156. [CrossRef]

19. Feng, Y.; Ryan, U.M.; Xiao, L. Genetic diversity and population structure of Cryptosporidium. Trends Parasitol. 2018, 34, 997-1011. [CrossRef]

20. Palmer, C.S.; Traub, R.J.; Robertson, I.D.; Devlin, G.; Rees, R.; Thompson, R.C.A. Determining the zoonotic significance of Giardia and Cryptosporidium in Australian dogs and cats. Vet. Parasitol. 2008, 154, 142-147. [CrossRef]

21. Lupo, P.J.; Langer-Curry, R.C.; Robinson, M.; Okhuysen, P.C.; Chappell, C.L. Cryptosporidium muris in a Texas canine population. Am. J. Trop. Med. Hyg. 2008, 78, 917-921. [CrossRef]

22. Giangaspero, A.; Iorio, R.; Paoletti, B.; Traversa, D.; Capelli, G. Molecular evidence for Cryptosporidium infection in dogs in Central Italy. Parasitol. Res. 2006, 99, 297-299. [CrossRef] [PubMed]

23. Li, W.; Feng, Y.; Santin, M. Host Specificity of Enterocytozoon bieneusi and Public Health Implications. Trends Parasitol. 2019, 35, 436-451. [CrossRef] [PubMed]

24. Li, W.; Xiao, L. Ecological and public health significance of Enterocytozoon bieneusi. One Health 2020, 12, 100209. [CrossRef]

25. Pan, W.; Wang, M.; Abdullahi, A.Y.; Fu, Y.; Yan, X.; Yang, F.; Shi, X.; Zhang, P.; Hang, J.; Li, G. Prevalence and genotypes of Giardia lamblia from stray dogs and cats in Guangdong, China. Vet. Parasitol. Reg. Stud. Rep. 2018, 13, 30-34. [CrossRef] [PubMed]

26. Zhang, Y.; Zhong, Z.; Deng, L.; Wang, M.; Li, W.; Gong, C.; Fu, H.; Cao, S.; Shi, X.; Wu, K.; et al. Detection and multilocus genotyping of Giardia duodenalis in dogs in Sichuan province, China. Parasite 2017, 24, 31. [CrossRef]

27. Qi, M.; Dong, H.; Wang, R.; Li, J.; Zhao, J.; Zhang, L.; Luo, J. Infection rate and genetic diversity of Giardia duodenalis in pet and stray dogs in Henan Province, China. Parasitol. Int. 2016, 65, 159-162. [CrossRef]

28. Li, W.; Liu, X.; Gu, Y.; Liu, J.; Luo, J. Prevalence of Cryptosporidium, Giardia, Blastocystis, and trichomonads in domestic cats in East China. J. Vet. Med. Sci. 2019, 81, 890-896. [CrossRef]

29. Kostopoulou, D.; Claerebout, E.; Arvanitis, D.; Ligda, P.; Voutzourakis, N.; Casaert, S.; Sotiraki, S. Abundance, zoonotic potential and risk factors of intestinal parasitism amongst dog and cat populations: The scenario of Crete, Greece. Parasit. Vectors 2017, 10, 43. [CrossRef]

30. Gil, H.; Cano, L.; de Lucio, A.; Bailo, B.; de Mingo, M.H.; Cardona, G.A.; Fernández-Basterra, J.A.; Aramburu-Aguirre, J.; López-Molina, N.; Carmena, D. Detection and molecular diversity of Giardia duodenalis and Cryptosporidium spp. in sheltered dogs and cats in Northern Spain. Infect. Genet. Evol. 2017, 50, 62-69. [CrossRef]

31. McDowall, R.M.; Peregrine, A.S.; Leonard, E.K.; Lacombe, C.; Lake, M.; Rebelo, A.R.; Cai, H.Y. Evaluation of the zoonotic potential of Giardia duodenalis in fecal samples from dogs and cats in Ontario. Can. Vet. J. 2011, 52, 1329-1333.

32. Fava, N.M.; Soares, R.M.; Scalia, L.A.; Cunha, M.J.; Faria, E.S.; Cury, M.C. Molecular typing of canine Giardia duodenalis isolates from Minas Gerais, Brazil. Exp. Parasitol. 2016, 161, 1-5. [CrossRef] [PubMed] 
33. Karim, M.R.; Don, H.; Yu, F.; Jian, F.; Zhang, L.; Wang, R.; Zhang, S.; Rume, F.I.; Ning, C.; Xiao, L. Genetic diversity in Enterocytozoon bieneusi isolates from dogs and cats in China: Host specificity and public health implications. Clin. Microbiol. 2014, 52, 3297-3302. [CrossRef]

34. Li, W.C.; Qin, J.; Wang, K.; Gu, Y.F. Genotypes of Enterocytozoon bieneusi in dogs and cats in eastern China. Iran. J. Parasitol. 2018, 13, 457-465. [PubMed]

35. Zhang, X.; Wang, Z.; Su, Y.; Liang, X.; Sun, X.; Peng, S.; Lu, H.; Jiang, N.; Yin, J.; Xiang, M.; et al. Identification and genotyping of Enterocytozoon bieneusi in China. J. Clin. Microbiol. 2011, 49, 2006-2008. [CrossRef] [PubMed]

36. Santín, M.; Trout, J.M.; Vecino, J.A.; Dubey, J.P.; Fayer, R. Cryptosporidium, Giardia and Enterocytozoon bieneusi in cats from Bogota (Colombia) and genotyping of isolates. Vet. Parasitol. 2006, 141, 334-339. [CrossRef] [PubMed]

37. Santín, M.; Cortés Vecino, J.A.; Fayer, R. Enterocytozoon bieneusi genotypes in dogs in Bogota, Colombia. Am. J. Trop. Med. Hyg. 2008, 79, 215-217. [CrossRef]

38. Al-Herrawy, A.Z.; Gad, M.A. Microsporidial spores in fecal samples of some domesticated animals living in Giza, Egypt. Iran. J. Parasitol. 2016, 11, 195-203.

39. Dengjel, B.; Zahler, M.; Hermanns, W.; Heinritzi, K.; Spillmann, T.; Thomschke, A.; Löscher, T.; Gothe, R.; Rinder, H. Zoonotic potential of Enterocytozoon bieneusi. J. Clin. Microbiol. 2001, 39, 4495-4499. [CrossRef]

40. Dashti, A.; Santín, M.; Cano, L.; de Lucio, A.; Bailo, B.; de Mingo, M.H.; Köster, P.C.; Fernández-Basterra, J.A.; Aramburu-Aguirre, J.; López-Molina, N.; et al. Occurrence and genetic diversity of Enterocytozoon bieneusi (Microsporidia) in owned and sheltered dogs and cats in Northern Spain. Parasitol. Res. 2019, 118, 2979-2987. [CrossRef]

41. Abe, N.; Kimata, I.; Iseki, M. Molecular evidence of Enterocytozoon bieneusi in Japan. J. Vet. Med. Sci. 2009, 71, 217-219. [CrossRef]

42. Piekarska, J.; Kicia, M.; Wesołowska, M.; Kopacz, Z.; Gorczykowski, M.; Szczepankiewicz, B.; Kváč, M.; Sak, B. Zoonotic Microsporidia in dogs and cats in Poland. Vet. Parasitol. 2019, 246, 108-111. [CrossRef] [PubMed]

43. Mori, H.; Mahittikorn, A.; Thammasonthijarern, N.; Chaisiri, K.; Rojekittikhun, W.; Sukthana, Y. Presence of zoonotic Enterocytozoon bieneusi in cats in a temple in Central Thailand. Vet. Parasitol. 2013, 197, 696-701. [CrossRef]

44. Lobo, M.L.; Xiao, L.; Cama, V.; Stevens, T.; Antunes, F.; Matos, O. Genotypes of Enterocytozoon bieneusi in mammals in Portugal. J. Eukaryot. Microbiol. 2006, 53, S61-S64. [CrossRef]

45. Jamshidi, S.H.; Tabrizi, A.S.; Bahrami, M.; Momtaz, H. Microsporidia in household dogs and cats in Iran; A zoonotic concern. Vet. Parasitol. 2012, 185, 121-123. [CrossRef] [PubMed]

46. Zhang, J.; Dong, H. Investigation of Parasite Infection in the Digestive Tract of Domestic Dogs in Zhengzhou. In Proceedings of the Academic Symposium of the Fourth Branch Association of Small Animal Medicine \& The Sixteenth Branch Association of Veterinary Surgery, Hohhot, China, 18 August 2009; pp. 226-229. Available online: https:/ / kns.cnki.net/kcms/detail/detail. aspx?FileName=ZGXJ200908003047\&DbName=CPFD2010 (accessed on 11 July 2021). (In Chinese).

47. Hu, L.; Qi, M.; Peng, G.; Zhong, Z.; Dong, H.; Zhang, L.; Liu, Y. Investigation of intestinal parasites infection in Ya'an City. Anim. Husb. Vet. Med. 2011, 10, 80-81.

48. Ito, Y.; Itoh, N.; Kimura, Y.; Kanai, K. Molecular detection and characterization of Cryptosporidium spp. among breeding cattery cats in Japan. Parasitol. Res. 2016, 115, 2121-2123. [CrossRef] [PubMed]

49. Sotiriadou, I.; Pantchev, N.; Gassmann, D.; Karanis, P. Molecular identifification of Giardia and Cryptosporidium from dogs and cats. Parasite 2013, 20, 8. [CrossRef]

50. Koompapong, K.; Mori, H.; Thammasonthijarern, N.; Prasertbun, R.; Pintong, A.; Popruk, S.; Rojekittikhun, W.; Chaisiri, K.; Sukthana, Y.; Mahittikorn, A. Molecular identifification of Cryptosporidium spp. in seagulls, pigeons, dogs, and cats in Thailand. Parasite 2014, 21, 52. [CrossRef] [PubMed]

51. Moreira, A.D.S.; Baptista, C.T.; Brasil, C.L.; Valente, J.S.S.; Bruhn, F.P.P.; Pereira, D.I.B. Risk factors and infection due to Cryptosporidium spp. in dogs and cats in southern Rio Grande do Sul. Rev. Bras. Parasitol. Vet. 2018, 27, 112-117. [CrossRef]

52. Simonato, G.; Frangipane di Regalbono, A.; Cassini, R.; Traversa, D.; Tessarin, C.; Cesare, A.D.; Pietrobelli, M. Molecular detection of Giardia duodenalis and Cryptosporidium spp. in canine faecal samples contaminating public areas in Northern Italy. Parasitol. Res. 2017, 116, 3411-3418. [CrossRef]

53. Overgaauw, P.A.; van Zutphen, L.; Hoek, D.; Yaya, F.O.; Roelfsema, J.; Pinelli, E.; van Knapen, F.; Kortbeek, L.M. Zoonotic parasites in fecal samples and fur from dogs and cats in the Netherlands. Vet. Parasitol. 2009, 163, 115-122. [CrossRef]

54. Colombo, M.; Morelli, S.; Simonato, G.; Cesare, A.D.; Veronesi, F.; di Regalbono, A.F.; Grassi, L.; Russi, I.; Tiscar, P.G.; Morganti, G.; et al. Exposure to major Vector-Borne Diseases in dogs subjected to different preventative regimens in endemic areas of Italy. Pathogens 2021, 10, 507. [CrossRef]

55. Morelli, S.; Colombo, M.; Dimzas, D.; Barlaam, A.; Traversa, D.; Cesare, A.D.; Russi, I.; Spoletini, R.; Paoletti, B.; Diakou, A. Leishmania infantum seroprevalence in cats from touristic areas of Italy and Greece. Front. Vet. Sci. 2020, 7, 616566. [CrossRef] [PubMed]

56. Morelli, S.; Crisi, P.E.; Cesare, A.D.; Santis, F.D.; Barlaam, A.; Santoprete, G.; Parrinello, C.; Palermo, S.; Mancini, P.; Traversa, D. Exposure of client-owned cats to zoonotic vector-borne pathogens: Clinicpathological alterations and infection risk analysis. Comp. Immunol. Microbiol. Infect. Dis. 2019, 66, 101344. [CrossRef] [PubMed]

57. Ortuño, A.; Scorza, V.; Castellà, J.; Lappin, M. Prevalence of intestinal parasites in shelter and hunting dogs in Catalonia, Northeastern Spain. Vet. J. 2014, 199, 465-467. [CrossRef] 
58. Berrilli, F.; D'Alfonso, R.; Giangaspero, A.; Marangi, M.; Brandonisio, O.; Kaboré, Y.; Glé, C.; Cianfanelli, C.; Lauro, R.; Cave, D.D. Giardia duodenalis genotypes and Cryptosporidium species in humans and domestic animals in Cote d'Ivoire: Occurrence and evidence for environmental contamination. Trans. R. Soc. Trop. Med. Hyg. 2012, 106, 191-195. [CrossRef] [PubMed]

59. Wang, S.S.; Wang, R.J.; Fan, X.C.; Liu, T.L.; Zhang, L.X.; Zhao, G.H. Prevalence and genotypes of Enterocytozoon bieneusi in China. Acta Trop. 2018, 183, 142-152. [CrossRef]

60. Ballweber, L.R.; Panuska, C.; Huston, C.L.; Vasilopulos, R.; Pharr, G.T.; Mackin, A. Prevalence of and risk factors associated with shedding of Cryptosporidium felis in domestic cats of Mississippi and Alabama. Vet. Parasitol. 2009, 160, 306-310. [CrossRef]

61. Cacciò, S.M.; Beck, R.; Lalle, M.; Marinculic, A.; Pozio, E. Multilocus genotyping of Giardia duodenalis reveals striking differences between assemblages A and B. Int. J. Parasitol. 2008, 38, 1523-1531. [CrossRef]

62. Xiao, L.; Morgan, U.M.; Limor, J.; Escalante, A.; Arrowood, M.; Shulaw, W.; Thompson, R.C.; Fayer, R.; Lal, A.A. Genetic diversity within Cryptosporidium parvum and related Cryptosporidium species. Appl. Environ. Microbiol. 1999, 65, 3386-3391. [CrossRef]

63. Ma, Y.T.; Zou, Y.; Liu, Q.; Xie, S.C.; Li, R.L.; Zhu, X.Q.; Gao, W.W. Prevalence and multilocus genotypes of Enterocytozoon bieneusi in alpacas (Vicugna pacos) in Shanxi Province, northern China. Parasitol. Res. 2019, 118, 1-5. [CrossRef] [PubMed]

64. Zhao, W.; Zhou, H.H.; Ren, G.X.; Qiang, Y.; Huang, H.C.; Lu, G.; Tan, F. Occurrence and potentially zoonotic genotypes of Enterocytozoon bieneusi in wild rhesus macaques (Macaca mulatta) living in Nanwan Monkey Island, Hainan, China: A public health concern. BMC Vet. Res. 2021, 17, 213. [CrossRef] [PubMed]

65. Santín, M.; Fayer, R. Enterocytozoon bieneusi genotype nomenclature based on the internal transcribed spacer sequence: A consensus. J. Eukaryot. Microbiol. 2009, 56, 34-38. [CrossRef] [PubMed] 